\title{
TEXTOS INDÍGENAS EN ESPAÑOL (S. XVIII). UN DOCUMENTO SOBRE LOS HECHICEROS DE TOLUCA
}

\author{
INDIGENOUS \\ DOCUMENTS IN \\ SPANISH (18TH \\ CENTURY). \\ A DOCUMENT \\ ABOUT \\ THE TOLUCA \\ SORCERERS
}


A lo largo del periodo colonial las comunidades indígenas fueron sometidas a las formas de administración castellana, lo que provocó que éstas participaran de la confección de textos tanto en sus lenguas como en español dada la importancia del documento escrito en el mundo occidental. Esta documentación es una fuente importante tanto para la elaboración de la historia de las comunidades indígenas como para el conocimiento de los usos lingüísticos en esos años. Por esto último, en este artículo presentamos la transcripción paleográfica de un legajo escrito por indígenas del valle de Toluca en español en el siglo XVIII, así como un breve análisis que apunta hacia la posible interferencia de la lengua náhuatl en esa variante de español.

Palabras Clave: contacto lingüístico, documentación indígena, español colonial

During the Spanish Colonial period, the indigenous communities were subjected to the Castilian administration manners; these caused that those communities took part in the making of texts written in their own languages and in Spanish, due to the significance of the written text in the occidental world. The documentation is important, on the one hand, for the writing of the history of the colonial period and as a source for the knowledge of the linguistic interaction during those years, on the other. Therefore, in this article we present the paleographic transcription of a file written by some Toluca Valley's indigenes in Spanish language. We also present a brief analysis that remarks the possible interference of the Nahua language over this particular variety of Spanish.

KEYWORDs: language contact, indigenous documentation, Colonial Spanish

FECHA DE RECEPCIÓN: 05/05/2016

FECHA DE ACEPTACIÓN: 16/07/2016 


\section{TEXTOS INDÍGENAS EN ESPAÑOL (S. XVIII). UN DOCUMENTO SOBRE LOS HECHICEROS DE TOLUCA ${ }^{1}$}

\section{INDIGENOUS DOCUMENTS IN SPANISH (18TH CENTURY). A DOCUMENT ABOUT THE TOLUCA SORCERERS}

Mauro Mendoza Posadas Facultad de Filosofía y Letras, UNAM

De la documentación colonial, la escrita por indígenas en lengua española ha sido en buena medida obviada; no es sino hasta ahora, gracias al proyecto COREECOM, que podemos contar con algunos documentos que se pueden revisar, por ejemplo, en volúmenes como el de Documentos públicos y privados del siglo XVI (Arias, 2015). En esta ocasión, es de nuestro interés dar a conocer un legajo del siglo XVIII escrito en Toluca.

Cabe mencionar que Toluca fue una zona de alta producción documental indígena, tanto en náhuatl como en español, por lo que ha sido muy atractivo para el estudio de fuentes con valor etnohistórico; volúmenes que recogen documentación en lengua náhuatl, como el de Pizzigoni (2007) y los estudios de Lockhart $(1988,1991)$ así lo demuestran.

\footnotetext{
${ }^{1}$ Esta investigación forma parte del Proyecto Conacyt св-2012/180245.
} 
El hecho de que el valle de Toluca, región en donde se hablaba el matlatzinca hasta el reinado de Axayácatl, posea una amplia documentación en esta lengua se explica a través de los propios procesos coloniales tanto mexicas como castellanos; fue durante el gobierno de este tlahtoani que el valle cayó bajo el dominio mexica y pronto hubo un poblamiento de la zona con habitantes de los altepeme que constituían la Triple Alianza, hablantes de la lengua náhuatl. Así lo reconoce García Castro:

tenemos informaciones de los indios del valle de Toluca del Siglo xvi que afirmaban que los señores de Tenochtitlán, Texcoco, Tacuba, Azcapotzalco y Tlatelolco habían, cada uno, mandado poblar con colonos de sus respectivas jurisdicciones las tierras y calpolli otomianos que Axayácatl había repartido o distribuido entre ellos (1999: 50).

Para Lockhart, "Nahuatl speakers were dominant, though apparently far from the most numerous group, by the time the Spanish conquerors arrived" (1991: 202). A ello debemos sumar que a este proceso de sustitución en el empleo de la lengua náhuatl por la española en el siglo XviII pertenece la documentación aquí expuesta (Lockhart, 1991: 105-121). Ahora bien, el documento fue realizado en un juzgado eclesiástico. Estos juzgados tenían a su cargo

la defensa de la jurisdicción eclesiástica y la dignidad episcopal; la disciplina de la clerecía; la justicia civil y criminal ordinaria de las personas eclesiásticas; la persecución de los delitos cometidos por los indios contra la fe; las causas de toda la población india y no 
india relacionadas con los "pecados públicos y escandalosos"; los asuntos concernientes o relativos a la vida matrimonial; velar por el cumplimiento de los compromisos de caridad con los vivos y los muertos patentes en los testamentos, capellanías y obras pías y los conflictos relativos a la administración de la renta decimal (Traslosheros, 2007: 371).

Y en tanto juzgados que eran, funcionaban de una manera parecida a como lo hacían otras instituciones jurídicas, por lo que las autoridades presentes aquí eran las mismas que en los otros juzgados. Es el escribano la autoridad que nos interesa, pues era él el encargado de confeccionar los dispositivos jurídicos, tomar las declaraciones y algunas veces fungir como intérprete. En muchos casos, los escribanos en comunidades indígenas formaban parte de dichas comunidades; esto no fue extraño en la medida que desde Las siete partidas alfonsíes se estipulaba que los escribanos fueran "vecinoz de aquellos lugares onde fueren Escriuanos, porque conozcan mejor los omes entre quien fizieren las cartas: e deuen ser legos, porque han de fazer cartas de pesquisas, o de otros pleitos" (Partida tercera, Título XIX, Ley II, apud Luján, 1982: 49). Esto implicó que hubiera indígenas que se desarrollaran como escribanos; ellos fueron "entrenados en las escuelas conventuales, [...] supieron utilizar el alfabeto castellano para reproducir los sonidos de sus lenguas y exponer memoriales de méritos o quejas de las comunidades" (Gonzalbo, 1990: 135). Sin duda, aunque desconocemos cómo fue el proceso en el que se formaron los escribanos indígenas, es cierto que estos participaron en las instituciones coloniales; además, aunque el conoci- 
miento de la escritura no se encontrara generalizado, como dice Dávalos, "letrados o no, participaban [los indígenas] de una cultura escrita que sabían cómo emplear" (2009: 112). Cabe decir aquí que hubo indígenas que, por una parte, tuvieron un cargo de escribanía en la sociedad colonial, y, por otra, que en los procesos judiciales no sólo fueron los indios escribanos los que tomaron la pluma, pues, como afirma Borah, que aunque la petición inicial en los juzgados fuera a veces escrita por un agente indio, otras era escrita "por el propio quejoso y a veces por un amigo suyo" (1985: 258). Creemos que esto último caracteriza al documento que aquí presentamos.

El caso de este legajo es muy significativo en la medida en que parece mostrar tres diferentes manos indígenas que intervinieron en su elaboración, además de la del notario. Temáticamente, es un texto bastante interesante, pues se trata de un auto de fe por hechicería en contra de Jacinto de Tapia, indio del pueblo de San Mateo en la Doctrina de Toluca, contra el que se querella Jacinto Nicolás, indio del pueblo de San Lorenzo, también de la Doctrina de Toluca, por haber el primero hechizado a la esposa del segundo al tratar de curarla de "una llaga o tumor". A lo largo del legajo podemos seguir el proceso judicial que culmina con la aprehensión de Jacinto de Tapia, quien parece que escribe su defensa desde la cárcel. Además de ellos dos, otro indio, Andrés Martín, del pueblo de San Pedro Totoltepec, también preso, parece haber participado con la hechura del folio $4 \mathrm{r}$ hasta la línea 25; sin embargo, la duda nace de la expresión con la que signa su firma, es decir, con la fórmula "no sé firmar", por lo que no lo consideraremos dentro de las notas que agrega- 
mos después de la transcripción como si se tratara de un documento escrito por un indígena. Cabe decir que aquí consideramos como documentos indígenas escritos en español aquellos en los que hay una intervención por parte de mano de un indígena; no hemos tomado en cuenta aquellos en los que es evidente que participa un notario, que suele escribir en tercera persona las declaraciones de quienes se presentan en el juzgado y que suele emplear fórmulas como 'dijo'. En esos casos, el que participa de la ejecución del documento es el notario, como el licenciado Juan del Villar en este legajo, y los textos pueden acaso arrojarnos datos sobre su variante, pero no sobre la interferencia de otra lengua en el español. Cabe decir también que no podemos eliminar la posibilidad de que fuera algún otro escribano el que está tomando la declaración - en este caso tendrían que ser dos distintos, uno que toma la declaración de Jacinto Nicolás y otro la de Jacinto de Tapia- pero en definitiva los escribanos muestran características de interferencia de otra lengua, como se verá más abajo.

El legajo se encuentra en el Archivo Histórico del Arzobispado de México, bajo la referencia Juzgado Eclesiástico de Toluca/ Lic. Juan del Villar/ Autos por maleficio/ Caja 75 , expediente 9 , y está fechado en 1756 . Se encuentra compuesto por 6 folios; los folios 1r, 1v, 3r y $3 \mathrm{v}$ fueron escritos por Jacinto Nicolás y Jacinto de Tapia escribió el folio 6r. El resto del legajo está compuesto por las declaraciones de otros indígenas que fueron tomadas por el licenciado Juan del Villar, cuya filiación étnica también desconocemos, pero independientemente de ello, lo que sí sabemos es que no sabía náhuatl puesto que requiere, en el f. $4 \mathrm{v}$, de la presencia 
de un intérprete, Marcos de San Juan, para tomar la declaración de Don Cayetano Matías, quien fuera alcalde del pueblo de San Pedro Totoltepec.

Esperamos, con el rescate documental, contribuir a trazar la historia del español en el centro de México y a documentar una variante que poco ha aparecido en la conformación de corpora coloniales. A continuación presentamos la transcripción de las partes del documento que han sido escritas por indígenas. La transcripción la hicimos según las normas del proyecto COREECOM ${ }^{2}$ para posteriormente realizar un breve análisis; para una revisión más detallada de éste y otros legajos, véase Mendoza, 2016.

\section{Archivo: Archivo Histórico del Arzobispado de México}

Referencia: Juzgado Eclesiástico de Toluca/ Caja 75, expediente 9

Zona geográfica: Centro

Origen dialectal: Desconocido

Origen étnico/social: Indígena

Sexo: Masculino

Tipo de documento: Formal

Variedad textual: Jurídico

\footnotetext{
${ }^{2}$ El principal interés del proyecto es convertir al documento en una fuente de datos lingüísticos, por lo que es necesario realizar dos transcripciones distintas: una paleográfica, altamente fiel al original tanto en la aparición de caracteres particulares (por ejemplo, el contraste entre 's', ' $\sigma$ ' y ' $\int$ '), la juntura de palabras, la estructura del documento, etc., lo que permite la realización de estudios de grafemática y fonología, y una presentación crítica, en donde la mano del editor aparece con el fin de facilitar la lectura y la realización de análisis de orden léxico y sintáctico. Para más especificaciones de los criterios de transcripción, Arias, 2015: 30-40.
} 
Periodo: 1751-1775

Año: 1756

Destinatario: Vuestra Magestad

Recopilación y edición: Mauro Alberto Mendoza Posadas

Presentación paleográfica

1. +

2. De fee:

3. Jasintho Nicolas marido legmo de Marcela Maria, indios

4. del Pueblo de sn lorenso de esta Doctrina de toluca, en la

5. mejor forma que proseda paresco ante Vm. y Digo: que

6. Jasintho de tapia, indio del Pueo de sn Matheo, y gañan

7. dela haCienda de la Magna de Dn Manuel de Ybarra, me ha

8. solicitado, diciendome ser de orden de Vm. para que de

9. rason de lo que me apasado, con dho Jasintho tapia, y

10. con Andres, yndio del Pueblo de Sn Pedro totoltepec, preso

11. en la carsel de esta Ciudad, apedimto de dho tapia, el que

12. hallandose, mi muger enferma de un tumor o inchason

13. en la garganta, y lleuando yo unos medicamntos para cu

14. rarlo que compre en la Botica de resepta de Dn Manuel 
15. casillas aora alo que me puedo acordar como mas de que

16. no al? me encontro dho Jasinto tapia, en la calle Rl. y

17. preguntandome, que llebaba y dandole rason $\mathrm{q}$ eran medi

18. camtos para mi muger, me dijo, que lo conuidara ame

19. dio de pulque y el me curaria ami muger y en efecto

20. le di el medio de pulque, y otro dia lunes fue a mi cassa

21. y empeso a curarla, y le puso en un papel una untacia o em

22. plaste, que el hiso y yo nose de q fue echo opuso sobre el

23. papel unas creeses?, y aunque la estubo curando algun tiempo

24. no consiguio el q sanara, mi muger; y aora por el mes de Di

25. siembre, del año que aora paso, teniendo yo noticia del dho An

26. dres que esta preso, que sauia curar, de la garganta, lo fuimos a

27. uer mi muger y Yo, y hauiendola reconosido, y puestola? en

28. cura, por algunos días, y viendo que no sanaba, le dijo $\mathrm{q}$

29. estaba echisada, y que quien le hacia el daño era Jasin

1. +

2. tho tapia, el que biuia junto aella, y que esto se lo dije

3. ra, y queel lo decia, que quien la tenia echisada

4. erael dho tapia, yenefecto le dijimos a dho Jasintho 
5. tapia lo que nos dijo dho Andres y lo que dixe a Vm

6. y otro? siendo necesario, en su cara, y que dho tapia asido

7. castigado, por este jusgado, por causa <ilegible > esta, $\mathrm{y}$

8. suplico a Vm mande adho Jasintho, no me moleste, ni ami

9. muger, ni perjudique en manera alguna sobre, el par

10. ticular, y protestamos mi muger y yo estar de pronto

11. para lo que Vm fuere seruido mandarnos sobre

12. el asumpto contenido en este escripto, portanto yde

13. mas faborable que he aqui por expre? estando alo fa

14. borable y negando lo perjudicial

15. A Vm fupco fe firua de hacer como pido, y juro en deuida

16. forma lo aqui contenido, ser sierto y no de malicia

17. yen lo necesario etc $=$

1. +

2. Supco se lea todo yse

3. me mire como pobre

4. Jasintho Nicolas marido legmo de Marcela Maria

5. indios del Pueblo de sanlorenso de esta Doctrina de to

6. luca preso en el capitulo, del conuto en la mejor forma q

7. puedo, y digo: que hauiendo o currido, a el llamado de $\mathrm{Vm}$

8. y declarado por mi ante sedente escrito, que Jasinto de

9. tapia, el propio se me ofresio a curar ami muger dela 
10. enfermedad, que padese, y la que no es de malefisio

11. sino enfermedad, que dios N.S. asido seruido, que pa

12. desca, y dela q la estaba curando el Mro de Cirujano

13. Dn Manuel Casillas, yaunque consenti que la curase

14. de ella, el referido Jasintho de tapia, fue por que el

15. mesmo se ofresio como tengo dicho en mi ante sedente

16. escripto, a curarla, y yo nolo solicite para quelo hisi

17. era, ni consenti en que la curara con malisia, ni sospecha

18. de que lo executara, por modo illisito, y aunque tam

19. bien, la curo, Andres, indio del Pueblo de sn Pedro totol

20. tepec, lo hiso porque tambien seofrsio a ello, graotota?

21. mente iendo a bender a mi Pueblo sus petates y llegan

22. do a mi casa y viendo, a mi muger enferma, dijo la cu

23. raria, y por lo que aber? cosa, de sanar lo solisitamos en

24. su cassa, y por hauerse el mesmo Andres ofresido

25. acurarla, sin que $<$ mancha $>$ ninguna persona nos di

26. jere que dho Andres era curandero pues aunque mi

27. muger, preguntada de Vm. Que quien nos hauia

28. dicho, que dho Andres era curandero, hauia respon

29. dido, que vna sobrina suia, les auia dado, noticia

$\{3 v\}$

1. +

2. de dho Andres, lo dijo perturbada, y miedusa, de uerse

3. en presensia dela justicia, y que lo que aora se desdi

4. se de ello, y por que ninguna persona nos dijo que 
5. buscasemos adho Andres para q la curara, sino que

6. el mesmo Andres se ofresio haserlo, como lleuo expre

7. sado, en cura asension, yano hauer admitido el $\mathrm{q}$

8. curasen, los dhos Andres y Jasintho, a mi muger, con

9. malisia, de que lo pudieran haser con modo illisito

10. y atendiendo la integridad de Vm apadeser en la

11. prision o? ensierro en que me hallo, sin culpa, yaes

12. tar hasiendo, falta en mi cassa ami muger e hijos

13. y deno poder sembrar en tiempo mis tierras, por lo

14. que si se quedan sin sembrar, no tendremos que

15. comer, ni conque poder pagar las pensiones de tri

16. butos y obensiunes, y tambien están hasiendo falta

17. en la haZienda que sirbo ami amo por ser bue

18. llero de ella, seade seruir Vmd de mandarlea

19. suelto de la prision enque me hallo, protestando

20. estar de manifiesto yaderecho para cada y para?

21. do que $\mathrm{Vm}$ me mande venir asu presensia

22. y que sea nesesario haserlo y por tanto

23. A Vm supco se sirua de hacerlo, como pido, enque

24. reseuire vien y mag con justicia, juro enforma

25. y en lo nesesr etc

1. +

2. Sr Jues eclesiástico

3. Jacinto de tapia yndio del Pueblo de Sn Mateo besino

4. deesta ciudad de Sr Sn Joseph de Toluca paresco ante Vmd 
5. y me querello con el dho Jacinto Nicolas y meconfiesso como

6. christiano queeste dho Jasinto trabajamos los dos juntos en la

7. hasienda demiamo Señor Dn Manoel de ybara y siempre

8. andamos los dos abeber yessierto queel meandaba rogan

9. do que yo le coran? A somojer y con las penas que Vmd me

10. dio y los castigos quello pase deese miedo metiami Pueblo en

11. San Mateo y este dho Jasinto Nicolas hasta que fie enpos

12. de Mi y llebo una bela deamedio enmicasa para quello le

13. core a so mojer que me confiesso como christiano que le

14. pose en <ilegible $>$ deamarillo delallaga quetiene y porqueno

15. se poede sanar dice este dho Andres del Pueblo de Sn

16. pedro que llo loanachise a so mojer dejasinto Nicolas

17. dise estdho Andres quenosabenada pos como lo sabeque

18. yo lo anachise esta mojer que este dho Andres loanda

19. linpiando esta dha mojer yporque estapicado conmi

20. go Andres le dixo ajasinto Nicolas quemelo dixiera

21. en mi cara quello lo anachise esta mojer y conlara

22. zon quello le diera ajasintoNicolas que leabisaran

23. este dhoAndres queporesso mepresente con vmd 
24. y queme de restigos y es Perola caridad de vmd=

\section{Presentación crítica}

$\{1 \mathrm{r}\}$ In Dei Nomine $/{ }^{1}<$ mano1 margen $>$ De fe: $/{ }^{2}$ Jasinto Nicolás, marido legítimo de Marcela Maria, indios ${ }^{3}$ del Pueblo de San Lorenso de esta Doctrina de Toluca, en la $/{ }^{4}$ mejor forma que proseda paresco ante Vuestra Merced. y digo: que $/{ }^{5}$ Jasinto de Tapia, indio del Pueblo de San Mateo y gañan ${ }^{6}$ de la hazienda de la Magdalena de Don Manuel de Ibarra, me ha/ $/ 7$ solicitado, diciéndome ser de orden de Vuestra Merced para que dé $/{ }^{8}$ rasón de lo que me a pasado con dicho Jasinto Tapia, $\mathrm{y}^{9}$ con Andrés, indio del Pueblo de San Pedro Totoltepec, preso $/{ }^{10}$ en la cársel de esta Ciudad, a pedimento de dicho Tapia, el que $/{ }^{11}$ hallándose mi muger enferma de un tumor o inchasón $/{ }^{12}$ en la garganta, y llevando yo unos medicamentos para $\mathrm{cu}-/^{13}$ rarlo que compré en la Botica de resepta de Don Manuel/ ${ }^{14}$ casillas abra? a lo que me puedo acordar como más de que $/{ }^{15}$ no al? me encontró dicho Jasinto Tapia en la calle Real, y/ ${ }^{16}$ preguntándome qué llebaba y dándole rasón que eran medi- ${ }^{17}$ camentos para mi muger, me dijo que lo convidara a me- $/{ }^{18}$ dio de pulque y él me curaría a mi muger; y en efecto/ $/{ }^{19}$ le di el medio de pulque y otro díoa lunes fue a mi casa/ $/{ }^{20} \mathrm{y}$ empesó a curarla, y le puso en un papel una untacia o em- ${ }^{21}$ plaste que él hiso y yo no sé de que fue chcio? o puso sobre el/22 papel unas creeses?, y aunque la estubo curando algún tiempo/23 no consiguió el que sanara mi muger; y aora por el mes de Di/24 siembre del año que aora pasó, teniendo yo noticia 
del dicho An- $/^{25}$ drés, que está preso, que savía curar de la garganta, lo fuimos a $/{ }^{26}$ ver mi muger y yo, y haviéndola reconosido, y puéstola? en/27 cura por algunos días, y viendo que no sanaba, le dijo que/28 estaba echisada, y que quien le hacia el daño era Jasin- ///29 $\{1 \mathrm{v}\}$ In Dei Nomine/ ${ }^{1}$ to Tapia, el que bivía junto a ella, y que esto se lo dije- $/^{2}$ ra, y que él lo decía, que quien la tenía echisada $/{ }^{3}$ era el dicho Tapia; y en efecto le dijimos a dicho Jasinto/ ${ }^{4}$ Tapia lo que nos dijo dicho Andrés y lo que dixe a Vuestra Merced $/ 5$ y otro? siendo necesario, en su cara, y que dicho Tapia a sido $/{ }^{6}$ castigado, por este jusgado, por causa $<$ ilegible $>$ a ésta, $y / /^{7}$ suplico a Vuestra Merced mande a dicho Jasintho no me moleste, ni a $\mathrm{mi} /{ }^{8}$ muger, ni perjudique en manera alguna sobre el par- $/^{9}$ ticular, y protestamos mi muger y yo estar de pronto $/{ }^{10}$ para lo que Vuestra Merced fuere servido mandarnos sobre $/{ }^{11} \mathrm{el}$ asumpto contenido en este escripto, por tanto y de-/ $/ 12$ más faborable que he aquí por expre? estando a lo fa- $/{ }^{13}$ borable y negando lo perjudicial $/ /{ }^{14}$ A Vuestra Merced suplico se sirva de hacer como pido, y juro en devida $/{ }^{15}$ forma lo aquí contenido, ser sierto y no de malicia $/{ }^{16} \mathrm{y}$ en lo necesario, etcétera.//17

$\{3 r\}$ In Dei Nomine $/{ }^{1}$ Suplico se lea todo y se $/{ }^{2}$ me mire como pobre:///3 Jasinto Nicolás marido legítimo de Marcela Maria, $/ 4$ indios del Pueblo de San Lorenso de esta Doctrina de To- $/^{5}$ luca, preso en el capítulo del convento, en la mejor forma que $/{ }^{6}$ puedo y digo: que haviendo ocurrido, a el llamado de Vuestra Merced $/{ }^{7}$ y declarado por mí ante sedente escrito, que Jasinto de $/^{8}$ Tapia, el propio se me ofresió a curar a mi muger de la $/{ }^{9}$ enfermedad que padese, y la que no 
es de malefisio $/{ }^{10}$ sino enfermedad que dios Nuestro Señor a sido servido que pa- $/{ }^{11}$ desca, y de la que la estaba curando el Maestro de Cirujano, $/{ }^{12}$ Don Manuel Casillas, y aunque consentí que la curase $/{ }^{13} \mathrm{de}$ ella el referido Jasinto de Tapia, fue porque él/ $/{ }^{14}$ mesmo se ofresió como tengo dicho en $\mathrm{mi}$ ante sedente $/{ }^{15}$ escripto, a curarla, y yo no lo solicité para que lo hisi- $/{ }^{16}$ era, ni consentí en que la curara con malisia, ni sospecha $/{ }^{17}$ de que lo executara por modo ilísito, y aunque tam- $/^{18}$ bién la curó Andrés, indio del Pueblo de San Pedro Totol- $/{ }^{19}$ tepec, lo hiso porque también se ofresió a ello, graotota?- $/ 20$ mente yendo a bender a mi Pueblo sus petates y llegan- ${ }^{21}$ do a mi casa y viendo, a mi muger enferma, dijo la cu- $/^{22}$ raría, y por lo que aber? cosa, de sanar lo solisitamos en $/{ }^{23}$ su casa, y por haverse el mesmo Andrés ofresido $/{ }^{24}$ a curarla, sin que $<$ mancha $>$ ninguna persona nos di- $/ 25$ jere que dicho Andrés era curandero pues aunque mi/26 muger, preguntada de Vuestra Merced que quien nos había $/{ }^{27}$ dicho que dicho Andrés era curandero, havía respon- $/{ }^{28}$ dido, que una sobrina suya les avía dado noticia///29

$\{3 \mathrm{v}\}$ In Dei Nomine $/^{1}$ de dicho Andrés, lo dijo perturbada, $y$ miedusa de verse $/^{2}$ en presensia de la justicia, y que lo que aora se desdi- $/ 3$ se de ello, y porque ninguna persona nos dijo que/ ${ }^{4}$ buscásemos a dicho Andrés para que la curara, sino que $/ 5$ el mesmo Andrés se ofresió haserlo, como llevo expre- $/{ }^{6}$ sado, en cura asension, y a no haver admitido el que- $/{ }^{7}$ curasen, los dichos Andrés y Jasinto, a mi muger con $/{ }^{8}$ malisia, de que lo pudieran haser con modo ilísito $/{ }^{9}$ $\mathrm{y}$ atendiendo la integridad de Vuestra Merced a padeser en la $/{ }^{10}$ prisión o ensierro en que me hallo, sin culpa, y a es- 
$/{ }^{11}$ tar hasiendo falta en mi casa a mi muger e hijos $/{ }^{12} \mathrm{y}$ de no poder sembrar en tiempo mis tierras, por lo/ ${ }^{13}$ que si se quedan sin sembrar, no tendremos qué $/{ }^{14}$ comer, ni conque poder pagar las pensiones de tri-/ ${ }^{15}$ butos y obensiunes, y también están hasiendo falta/ ${ }^{16}$ en la hazienda que sirbo a mi amo por ser bue- $/{ }^{17}$ llero de ella. Se a de servir Vuestra Merced de mandarle a- $/{ }^{18}$ suelto de la prisión en que me hallo, protestando $/{ }^{19}$ estar de manifiesto y a derecho para cada y para?/20 do que Vuestra Merced me mande venir a su presencia/ ${ }^{21} \mathrm{y}$ que sea nesesario haserlo y por tanto://22 $\mathrm{A}$ Vuestra Merced suplico se sirva de hacerlo, como pido, en que $/{ }^{23}$ reseviré? vien y merced con justicia, juro en forma $/{ }^{24}$ y en lo nesesario, etcétera.///25

\{6r\} In Dei Nomine// ${ }^{1}$ Señor Jues Eclesiástico://2Jacinto de Tapia, indio del Pueblo de San Mateo, besino/ ${ }^{3}$ de esta Ciudad de Señor San Josef de Toluca, paresco ante Vuestra Merced $/{ }^{4}$ y me querello con el dicho Jacinto Nicolás y me confiesso como $/{ }^{5}$ cristiano que este dicho Jasinto trabajamos los dos juntos en la $/{ }^{6}$ hasienda de mi amo, Señor Don Manoel de Ibara y siempre $/^{7}$ andamos los dos a beber y es sierto que el me andaba rogan $-/^{8}$ do que yo le coran a so mojer y con las penas que Vuestra Merced me/ ${ }^{9}$ dio y los castigos que llo pasé de ese miedo metí a mi Pueblo en $/{ }^{10}$ San Mateo, y este dicho Jasinto Nicolás hasta que fue en pos $/{ }^{11}$ de mí y llebó una bela de a medio en mi casa para que llo le $/{ }^{12}$ core a so mojer, que me confieso como cristiano que le $/{ }^{13}$ pose en $<$ ilegible $>$ de amarillo de la llaga que tiene, y porque no $/{ }^{14} \mathrm{se}$ poede sanar dice este dicho Andrés del Pueblo de San $/{ }^{15} \mathrm{Pe}-$ dro que llo lo anachise a so mojer de Jasinto Nicolás $/{ }^{16}$ dise 
este dicho Andrés que no sabe nada; pos cómo lo sabe que/ ${ }^{17}$ yo lo anachise esta mojer, que este dicho Andrés lo anda/ ${ }^{18}$ limpiando esta dicha mojer, y porque está picado conmi-/ ${ }^{19}$ go, Andrés le dixo a Jasinto Nicolás que me lo dixiera/ ${ }^{20}$ en mi cara que llo lo anachise esta mojer, y con la ra- $/{ }^{21}$ zón que llo le diera a Jasinto Nicolás que le abisaran/22 este dicho Andrés que por eso me presenté con Vuestra Merced/ ${ }^{23}$ y que me dé testigos y espero la caridad de Vuestra Merced.///24

\section{Comentario}

Ahora realizaremos algunas breves notas sobre el documento, según tres niveles de análisis que nos parecen fundamentales para describir las características de la lengua escrita de cada uno de los productores; a saber: nivel gráfico-fonético, morfosintáctico y léxico.

\section{Jacinto Nicolás, Ff. 1r-1v y 3r-3v}

a) Nivel gráfico-fonético

Mucho de lo que podemos constatar en el documento no es particular de este escribiente, sino que es algo reiterado en las variantes latinoamericanas del español en su totalidad, así como en las variantes andaluza y canaria. Tal es el caso del evidente seseo que se observa en todo el documento en el uso indiscriminado de las grafías 's', 'c' y ' $z$ ' para representar el fonema /s/, como es el caso de 'Jasintho', 'Lorenso', 
'hazienda', 'jusgado', 'carsel', etc.,' lo mismo ocurre con la confusión de 'b', 'v' y 'u', este último con valor consonántico, para la representación de /b/ y su alófono fricativo, como en los casos en que Jacinto Nicolás escribe 'biuia', 'conuidara', 'conuto', etc. ${ }^{4}$ Asimismo, también se constata el empleo de las grafías 'y' e 'i' para la representación del fonema /y/: 'iendo' y 'suia'; estos dos últimos casos pueden deberse al mantenimiento de la tradición de escritura castellana. ${ }^{5}$

En el documento se observan también dos casos de cambio de la grafía de la vocal anterior alta /i/ por la grafía de la media /e/. El caso en el que esto se constata es en la palabra 'mesmo', que aparece tres veces, por lo que también podría

\footnotetext{
${ }^{3}$ Respecto al seseo, sabemos que está documentado desde el siglo xvi y que, principalmente, se debe a la neutralización de la oposición sonoro/sordo que se perdió en todas las variantes del castellano, lo que generó diversos resultados fonológicos; para la confusión incluso ortográfica de este fenómeno, véase Arias, 1997.

${ }^{4}$ Por su parte, la neutralización de una posible fricativa bilabial sonora y la oclusiva con el mismo punto y modo de articulación en español se remonta hasta la época medieval de la lengua; la confusión ortográfica, por lo tanto, no se corresponde con la confusión de dos fonemas que mucho tiempo antes se habían fusionado en /b/, sino que se corresponde con el mantenimiento de una tradición de escritura, o con el posible desconocimiento de la misma (Penny, 1993: 94 y ss).

${ }^{5}$ En lo tocante al empleo de ' $v$ ' y 'u' para representación tanto de /u/ como de $/ \beta /$, Sánchez-Prieto reconoce este uso como una tradición ya presente por lo menos en el siglo XIII, lo mismo que reconoce también ya en El fuero de Alcalá la confusión entre 'b' y 'v' a inicio de palabra. Sobre el uso de ' $y$ ' e 'i' con el valor de $/ y /$, el mismo Sánchez-Borja apunta que el "empleo de $i$ con valor mediopalatal en maior o suio, [es] rarísimo en la cancillería de Fernando III y en toda la producción alfonsí (1 caso en GE4, suia; Torrens 2002: 134), pero presente en el Auto de los Reyes Magos (io, maior), en el Fuero de Alcalá y en las tradiciones monásticas castellanas durante la primera mitad del s. xIII, y en algunas como la de San Salvador de Oña, durante todo el siglo. En el s. xiv se observa un cierto auge de este uso, que llegará a hacerse corriente en los siglos XV y Xvi" (2005: 434).
} 
considerarse el fenómeno como un arcaísmo que caracterizara al habla rural del centro de México o la continuación de una tradición de escritura; hay que advertir que el CORDE registra 874 casos de 'mesmo' después de 1700, la gran mayoría de ellos en la península ibérica, mientras que en México no aparece ninguno. Esto es lo mismo que sucede con la forma 'reseuire'. Otro caso notorio es el empleo de la grafía 'u', que representa el fonema /u/, para la representación de la también posterior /o/ en dos casos del documento: 'miedusa' y 'obensiunes'; respecto a la confusión de vocales hablaremos más adelante.

\section{b) Nivel morfosintáctico}

En este nivel lo que más llama la atención es el particular uso de Jacinto Nicolás de los pronombres relativos del tipo "el que"; aunque, en efecto, en muchos casos de los observados en ambos folios el pronombre introduce la oración adjetiva tal como se esperaría, pero en otros casos no desempeña esta función. Pongamos atención a dos casos: el primero aparece en la línea $24 \mathrm{del} \mathrm{f} 1 \mathrm{r}$., "y aunque la estuvo curando algun tiempo, no consiguio el $q$ sanara, mi muger"; el segundo, aparece en la línea 8 de f. 3v: "yano hauer admitido el que curasen, los dhos Andres y Jasintho, a mi muger"; en ambos, la oración introducida por el pronombre relativo es, en verdad, una oración completiva y, en ambos casos, bastaría con que la conjunción "que" estableciera la relación de subordinación. Sin embargo, en otros contextos este pronombre se utiliza como relativo: "se me ofresio a curar ami muger dela enfermedad, que padece, y la que no es de malefisio". 
Además de estos casos, habría que observar algunos en las que las preposiciones no parecieran coincidir con el uso esperado; por ejemplo, al introducir al agente de una construcción pasiva en la línea 27 de 3r, se emplea la preposición "de" en vez de la preposición "por": "preguntada de Vm",6 lo que habla de un mantenimiento de un uso antiguo; asimismo, se puede observar un caso en que la preposición "a" y el determinante "el" no aparecen en su forma apocopada (hauiendo o currido, a el llamado de Vm), así como la variación entre la construcción "consentí en" y "consentî": "consentí que la curase" contra "consentí en que la curara".

El uso de futuro de subjuntivo está bien documentado en el género jurídico, incluso en nuestros días. En el documento lo podemos observar en la siguiente oración: "protestamos mi muger y yo estar de pronto para lo que a VM fuere seruido mandarnos".

\section{c) Nivel léxico}

Llama la atención el empleo de la palabra "obension", es decir, obvención, que es una "utilidad fija o eventual además del sueldo que se disfruta" (DRAE), de evidente registro jurídico, y que se encuentra registrada, según el CORDE, en un solo documento mexicano de 1640. De nahuatlismos, se puede registrar uno que es muy claro, "petate", del náhuatl "petlatl", que Simeón define como "estera sobre la cual los

\footnotetext{
6 Todavía hacia el siglo xv, parece que hay una competencia amplia entre las formas 'de' y 'por' como introductor del oblicuo agente de la voz pasiva; en un estudio al respecto, Ricós Vidal (1992) reconoce todavía la preferencia por el uso de 'de'. Sin embargo, durante los siglos posteriores la situación cambiará para el completo uso de la preposición 'por'.
} 
indios se sentaban y se costaban", 7 y otra cuya etimología es dudosa, pero que compone parte fundamental del léxico mexicano: "pulque". Moreno de Alba duda en que el étimo de esta palabra sea el náhuatl y apunta por lo menos otras dos posibilidades: una palabra araucana, $p u l c u$, con que se designa una bebida fermentada de maíz, o la palabra pucra del cumanagota, una lengua indígena venezolana, que designaría la parte interna de cogote; además, esta lengua está emparentada con las lenguas arahuacas, primeras con las que tuvieron contacto los conquistadores (2003). En todo caso, no es posible aceptar que se trate de una palabra nahua.

\section{Jacinto de Tapia, f. $6 r$}

a) Nivel gráfico-fonético
El yeísmo, el seseo y la confusión de 'b', 'v' y 'u' son, como
es de esperarse, comunes en este documento: 'besino', 'bela'.
Asimismo, el empleo de la grafía 'o' por 'u' es más que evi-
dente, lo que seguramente acusa una confusión entre /u/ y
/o/; el documento se encuentra plagado de estos casos: 'core',
'so', 'mojer', 'pose, 'poede.' También observamos la monop-

${ }^{7}$ Simeón, Diccionario de la lengua náhuatl o mexicana: redactado según los documentos y manuscritos más auténticos y precedido de una introducción (1997: 380).

${ }^{8}$ Este tipo de confusión vocálica suele atribuirse al sustrato indígena en muchas variantes del español. En efecto, por lo menos en lo que corresponde al náhuatl, la atribución parece correcta. El sistema vocálico del náhuatl es un sistema 'cuadrado' en el que /o/ es la vocal más posterior y más alta del sistema, mientras que /a/ la vocal posterior baja y /i/ y /e/ son las vocales anteriores. Véase Launey (1992). Flores Farfán (2012) registra el mismo fenómeno en comunidades nahuaparlantes del Balsas, en el estado de Guerrero. 
tongación de /we/>/o/ en formas como 'pos', o la presencia de hiato en 'poede'.

\section{b) Nivel morfosintáctico}

El documento muestra una serie de fenómenos importantes que no podemos dejar pasar por alto; uno de ellos, constante en el texto, es, primero, la reduplicación del oD a través del clítico "lo"; además de ello, el clítico no tiene concordancia de género con la frase que funciona como oD: "dise este dho Andres que llo loanachise a so mojer", "este dho Andres loanda limpiando esta dha mojer". De las veces en que se presenta esta construcción, seis en total, entre los que se encuentra el que apuntamos primero, en tres el od está introducido por la preposición "a", en las restantes, a pesar de ser un objeto animado, no aparece. Lo mismo ocurre en una ocasión con la introducción del or: "que leabisaran este dho Andres que por esso mepresente con vmd". Llama también la atención la aparición del denominado dativo ético en construcciones como: "quello le core a so mojer [a Andrés]".

La doble posesión también aparece en el documento: "lo anachise a so mojer dejasinto Nicolás", en la que la posesión se establece a partir del adjetivo posesivo y una frase prepositiva, aunque sólo se registra en este caso. También se observa el empleo particular de la preposición "en" en el

\footnotetext{
${ }^{9}$ Hemos conjuntado estos fenómenos bajo la categoría de "fenómenos del objeto" a causa de que el náhuatl es una lengua de Objeto Primario (Dryer, 1986), lo que explicaría el tratamiento similar para los oD y oI; además, la reduplicación se podría explicar a causa de que el náhuatl marca en su verbo obligatoriamente el objeto con un afijo particular, además de presentar, en ocasiones, la FN de ese objeto; véase Launey (1992).
} 
siguiente caso: "y llebo una bela deamedio enmicasa" con el valor de meta o, quizás, como la genérica marca de locativo. Otra construcción particular de este documento es la que se realiza con un doble adjetivo del tipo "este+dho+N": "esta dha mojer, este dho Andres, este dho Jasinto", que es una prolongación de la tradición medieval española (Barra Jover, 2008).

Finalmente, hay que apuntar que a pesar de que la correlación de tiempos exigiría el empleo de subjuntivo en varias de las construcciones, este jamás es empleado, así como tampoco los copretéritos y los pospretéritos. Las únicas formas verbales empleadas son el presente y el pretérito perfecto de indicativo, y una forma particular que pareciera tener un aspecto habitual construido con el verbo "andar": "siempre andamos los dos a beber", "[Andrés] loanda limpiando esta dha mojer". ${ }^{10}$

\section{c) Nivel léxico}

Llama la atención que Jacinto de Tapia utilice una forma de enhechizar con ciertos cambios fonéticos: anachisar. Esta palabra, a pesar de que está registrada en el DRAE, no aparece en el CORDE, por lo que es difícil saber si era muy empleada en la época; a pesar de ello, el escribiente del f. $2 \mathrm{r}$

\footnotetext{
${ }^{10}$ Lockhart (1991: 110 y ss.) hace el análisis de tres documentos escritos en español por indígenas de Toluca, a quienes también les atribuye el náhuatl como L1, y observa el mismo tipo de interferencias sintácticas (en el sentido más clásico del término) que las que apuntamos en este trabajo: falta de concordancia, ausencia de la preposición 'a' como marcador de oD y oI, reduplicación. En otro trabajo (Mendoza, 2016), hemos analizado detenidamente las razones de estas interferencias desde las características morfosintácticas de la lengua de 'sustrato', es decir, el náhuatl.
} 
del legajo también utiliza el verbo enhechizar en su forma de participio: "enechizada". A esto hay que sumar el empleo metonímico de la forma "de a medio" en la forma "una bela deamedio" que, presumiblemente, se refiere a medio real.

\section{A manera de conclusión}

Observamos aquí una serie de textos elaborados por manos indígenas. Este tipo de documentos nos permite rastrear el contacto que existió durante la Colonia en el español del centro de México con otras lenguas, particularmente con el náhuatl, que para la época de la conquista funcionaba ya como una lengua franca (Dakin, 2010) y que era ampliamente hablada en zonas como las del valle de Toluca, en donde había sido impuesta por la colonización nahua.

No es interés particular de este trabajo problematizar sobre el tipo de interferencia lingüística que observamos en el texto; si acaso el hecho de enunciar algunos rasgos pretende generar interés en investigadores y estudiantes para acercarnos a este tipo de documentación, tarea que por supuesto nace con el rescate documental y el trabajo archivístico.

También es cierto que en este tipo de documentación esperamos encontrar algunos reflejos matizados por la propia Tradición Discursiva - es decir, las formas tradicionales de, por ejemplo, escribir o conformar las formas anafóricas- de cómo pudo haber sido esa variante particular con un sustrato nahua, aunque por ahora esta otra vertiente de la investigación apenas comienza a trazarse. 
Asimismo, creemos necesario ampliar este tipo de estudio para observar el contacto de diferentes sustratos, sobre todo en el área maya, zapoteca y purépecha, pues obviar las diferencias entre estas lenguas y conjuntar el contacto entre el español y "las lenguas indígenas" (Moreno, 2001; Lipski, 1999) es reduccionista y ciego ante la realidad lingüística de la Nueva España y otras colonias americanas.

\section{Bibliografía}

Arias Álvarez, Beatriz (1997), "Nuevamente sobre las sibilantes", Anuario de Letras, XXXV, pp. 43-59.

Arias Álvarez, Beatriz (2015), Documentos públicos y privados del siglo XVI. Textos para la historia del español colonial mexicano. Maribel Rosa Delgado García, Mauro Alberto Mendoza Posadas e Idanely Mora Peralta, coolaboradores. México, Universidad Nacional Autónoma de México.

Barra Jover, Mario (2008), "Tradición discursiva. Creación y difusión de innovaciones sintácticas", en Sintaxis histórica del español y cambio lingüístico. Nuevas perspectivas desde las tradiciones discursivas, Madrid, Iberoamericana, pp. 127-150.

Borah, Woodrow (1985), El juzgado general de indios en la Nueva España, México, Fondo de Cultura Económica. DAKIN, Karen (2010), "Lenguas francas y lenguas locales en la época preshipánica”, en Historia sociolingüística de México, vol. 1., México, El Colegio de México, pp. 161-184. 
Dávalos, Marcela (2009), Los letrados interpretan la ciudad: Los barrios de indios en el umbral de la Independencia, México, INAH.

Dryer, Mathew (1986), "Primary objects, secondary objects and antidative", Language. 62, 4, pp. 808-845.

Flores FARfán, José Antonio (2012), Cuatreros somos y toindioma hablamos. Contactos y conflictos entre el náhuatl y el español en el sur de México, México, CIESAS. García CAstro, René (1999), Indios, territorio y poder en la provincia Matlatzinca: la negociación del espacio político de los pueblos otomianos, siglos XV-XVII. México, CIESAS.

Gonzalbo Aizpuru, Pilar (1990), Historia de la educación en la época colonial: el mundo indígena, México, El Colegio de México.

LAUney, Michel (1992), Introducción a la lengua y literatura náhuatl, México, Universidad Nacional Autónoma de México.

Lipski, John M. (1999), El español de América, Madrid, Cátedra.

LOCKHART, James (1988), “A language transition in Eighteenth Century in Mexico: The Change from Nahuatl to Spanish recordkeeping in the Valley of Toluca”, en Kathryn Josserand y Karen Dakin (eds.), Smoke and Mist: Mesoamerican Studies on Memory of Thelma D. Sullivan, vol. II, Oxford, BAR. Bar International Series 402 (II), pp. 571-584.

Lockhart, James (1991), Nahuas and Spaniards: postconquest central Mexican history and philology, Los Ángeles, Stanford University Press. 
Luján MuÑoz, Jorge (1982), Los escribanos en las indias occidentales, $3^{\text {a }}$ ed., nuevamente revisada y amapliada, México, Instituto de Estudios y Documentos Históricos y Universidad Nacional Autónoma de México.

Mendoza, Mauro (2016), "Voces indígenas en letras españolas: algunos aspectos morfosintácticos del contacto colonial", Lexis, 40, 1, pp. 167-184.

Moreno de Alba, José (2001), El español en América, México, Fondo de Cultura Eeconómia.

Moreno de Alba, José (2003), Suma de minucias del lenguaje, México, Fondo de Cultura Económica. Versión en línea en http://www.fondodeculturaeconomica. com/obras/suma/r3/buscar.asp

Penny, Ralph (1993), Gramática histórica del español, Baecelona, Arial.

Pizzigoni, Caterina (2007), Testaments of Toluca, Stanford, Stanford University Press.

Real Academia Española (2014), Diccionario de la lengua española, $23^{\text {a }}$ ed., Madrid, Espasa-Calpe.

Ricós Vidal, Amparo (1992), "La función del complemento agente de la construcción ser + participio en el español del siglo Xv", en Actas del II Congreso Internacional de Historia de la Lengua Española, tomo I, Madrid, Pabellón de España, pp. 785-793.

SÁnchez-Prieto, Pedro (2005), "La normalización del castellano escrito en el siglo XIII. Los caracteres de la lengua: grafía y fonema", en R. Cano Aguilar (coord.), Historia de la lengua española, Madrid, Ariel, pp. 423-448. Simeón, Rémi (1997), Diccionario de la lengua náhuatl o mexicana: redactado según los documentos impresos y 
manuscritos más auténticos y precedido de una introducción, 14ª ed., México, Fondo de Cultura Económica. Traslosheros, Jorge (2007), "El pecado y el delito. Notas para el estudio de la justicia criminal eclesiástica en la Nueva España del siglo Xviı", Jurípolis, 5, pp. 135-150. 